(c) The Authors 2015. This is an Open Access article, distributed under the terms of the Creative Commons Attribution licence (http:// creativecommons.org/licenses/by/3.0/), which permits unrestricted re-use, distribution, and reproduction in any medium, provided the original work is properly cited.

\title{
Selenium status in UK pregnant women and its relationship with hypertensive conditions of pregnancy
}

\author{
Margaret P. Rayman ${ }^{1 *}$, Sarah C. Bath ${ }^{1}$, Jacob Westaway ${ }^{2}$, Peter Williams ${ }^{3}$, Jinyuan Mao ${ }^{1}$, \\ Jessica J. Vanderlelie ${ }^{2}$, Anthony V. Perkins ${ }^{2}$ and Christopher W. G. Redman ${ }^{4}$ \\ ${ }^{1}$ Department of Nutritional Sciences, Faculty of Health and Medical Sciences, School of Biosciences and Medicine, \\ University of Surrey, Guildford GU2 $7 X H, U K$ \\ ${ }^{2}$ School of Medical Science, Griffith Health Institute, Griffith University, Queensland, QLD 4222, Australia \\ ${ }^{3}$ Department of Mathematics, Faculty of Engineering and Physical Sciences, University of Surrey, Guildford GU2 $7 X H$, UK \\ ${ }^{4}$ Nuffield Department of Obstetrics and Gynaecology, University of Oxford, Oxford OX3 9DU, UK \\ (Submitted 10 June 2014 - Final revision received 13 October 2014 - Accepted 17 October 2014)
}

\section{Abstract}

Dietary intake/status of the trace mineral Se may affect the risk of developing hypertensive conditions of pregnancy, i.e. pre-eclampsia and pregnancy-induced hypertension (PE/PIH). In the present study, we evaluated Se status in UK pregnant women to establish whether pre-pregnant Se status or Se supplementation affected the risk of developing PE/PIH. The samples originated from the SPRINT (Selenium in PRegnancy INTervention) study that randomised 230 UK primiparous women to treatment with Se $(60 \mu \mathrm{g} / \mathrm{d})$ or placebo from $12 \mathrm{weeks}$ of gestation. Whole-blood Se concentration was measured at 12 and 35 weeks, toenail Se concentration at 16 weeks, plasma selenoprotein P (SEPP1) concentration at 35 weeks and plasma glutathione peroxidase (GPx3) activity at 12, 20 and 35 weeks. Demographic data were collected at baseline. Participants completed a FFQ. UK pregnant women had whole-blood Se concentration lower than the mid-range of other populations, toenail Se concentration considerably lower than US women, GPx3 activity considerably lower than US and Australian pregnant women, and low baseline SEPP1 concentration (median 3.00, range $0 \cdot 90-5 \cdot 80 \mathrm{mg} / \mathrm{l}$ ). Maternal age, education and social class were positively associated with Se status. After adjustment, whole-blood Se concentration was higher in women consuming Brazil nuts $(P=0.040)$ and in those consuming more than two seafood portions per week $(P=0.054)$. A stepwise logistic regression model revealed that among the Se-related risk factors, only toenail Se (OR $0 \cdot 38,95 \%$ CI $0 \cdot 17,0 \cdot 87, P=0 \cdot 021)$ significantly affected the OR for PE/PIH. On excluding non-compliers with Se treatment, Se supplementation also significantly reduced the OR for PE/PIH (OR $0.30,95 \%$ CI $0.09,1.00, P=0.049)$. In conclusion, UK women have low Se status that increases their risk of developing PE/PIH. Therefore, UK women of childbearing age need to improve their Se status.

\section{Key words: Selenium status: Pregnancy: Hypertension: Hypertensive conditions of pregnancy}

As many as $10 \%$ of women are affected by high blood pressure in pregnancy and some $2-5 \%$ will go on to develop proteinuria, triggering a diagnosis of the more serious hypertensive condition, i.e. pre-eclampsia $(\mathrm{PE})^{(1,2)}$. Not only is $\mathrm{PE}$ associated with high maternal and fetal morbidity and mortality ${ }^{(1,2)}$, women who have had PE, or indeed pregnancy-induced hypertension $(\mathrm{PIH})$, have a greater risk of developing hypertension, stroke and IHD in later life ${ }^{(3-5)}$. Furthermore, they have daughters who are at an increased risk of developing the same pregnancy complications ${ }^{(6,7)}$ and children who are more likely to develop hypertension as adults ${ }^{(8)}$.
There are indications that dietary intake or status of the trace mineral Se may affect the risk of developing hypertensive conditions of pregnancy ${ }^{(9)}$. For instance, Chinese women supplemented with Se have been shown to have a lower risk of developing $\mathrm{PIH}^{(10)}$. A negative correlation has been found between Se status and the incidence of $\mathrm{PE}$ in an epidemiological study of forty-five countries ${ }^{(11)}$. Significantly lower levels of selenoenzymes such as glutathione peroxidase $(\mathrm{GPx})$ and thioredoxin reductase have been found in serum, plasma and placenta samples from pre-eclamptic women than in those from matched healthy controls ${ }^{(12-15)}$. Genetic evidence suggests that the

Abbreviations: DBP, diastolic blood pressure; GPx, glutathione peroxidase; GPx3, plasma glutathione peroxidase; PE, pre-eclampsia; PIH, pregnancyinduced hypertension; SEPP1, selenoprotein $\mathrm{P} ; \mathrm{T}_{\text {reg }}$ cells, regulatory $\mathrm{T}$ cells.

*Corresponding author: Professor M. P. Rayman, fax + 441483 686401, email m.rayman@surrey.ac.uk 
anti-inflammatory selenoprotein S (SELS) affects the risk of developing $\mathrm{PE}^{(16)}$.

In a previous UK study, we have found that the concentration of Se in toenails (laid down from 3 to 12 months previously) of women with $\mathrm{PE}$ is significantly lower than that of matched controls $(P=0 \cdot 001)^{(17)}$. That study triggered a pilot trial of Se supplementation in UK pregnant women that aimed to reduce biomarkers of $\mathrm{PE}$ risk $^{(9)}$. In that trial, we showed a significantly lower $(P=0.039)$ concentration of plasma soluble vascular endothelial growth factor receptor-1 (sFlt-1), a recognised biomarker of pre-eclampsia risk, at 35 weeks in the Se-treated group $(60 \mu \mathrm{g} / \mathrm{d}$ as Se yeast) than in the placebo group in participants of low Se status (lowest quartile) at baseline $^{(9)}$.

The present study used samples and data collected in that pilot trial. To establish the Se status, we used a range of measures at various gestational ages: (1) whole-blood Se concentration at baseline (12 weeks) and after 23 weeks of treatment with Se or placebo (35 weeks); (2) toenail Se concentration in clippings collected at 16 weeks (a measure of pre-pregnancy Se status); (3) plasma glutathione peroxidase (GPx3) activity at 12, 20 and 35 weeks; (4) plasma selenoprotein P (SEPP1) concentration at 35 weeks.

Our two hypotheses were that (1) UK pregnant women have low Se status, as determined by a number of parameters, and (2) pre-pregnant Se status or Se supplementation in pregnancy affects the risk of developing hypertensive conditions of pregnancy, i.e. PE or PIH, as a single outcome (PE/PIH).

\section{Experimental methods}

The selection of subjects has been described previously ${ }^{(9)}$. Women were excluded if they were under 18 years, current smokers, taking any supplement containing Se, taking thyroid medication, had a multi-fetal pregnancy or a number of other specified pregnancy complications, or withheld consent. Blood, plasma and toenail samples originated from the SPRINT (Selenium in PRegnancy INTervention) study (trial registration no. ISRCTN37927591) that randomised 230 primiparous women in Oxford, UK, to treatment with Se $(60 \mu \mathrm{g} / \mathrm{d}$ $\mathrm{Se}$, as Se yeast) or placebo (placebo yeast) from their first hospital antenatal visit (mean gestational age 12.3 weeks) until the delivery of the baby ${ }^{(9)}$. Blood samples, from which plasma was prepared, were collected at baseline (12 weeks), 20 and 35 weeks, while toenail clippings were collected at 16 weeks, as described previously ${ }^{(9)}$.

A FFQ was administered at recruitment and was completed by 219 women (95.6\% of the cohort). Meanwhile, clinical and demographic data, including weight and height (for calculation of BMI at baseline), date of birth (for calculation of maternal age at recruitment), age at which the education of the mother ceased, and occupation were recorded in order to explore the potential effect of a number of factors on Se status and on the development of PE/PIH.

$\mathrm{PIH}$ was defined as new hypertension appearing for the first time after 20 weeks of pregnancy. Hypertension was defined as diastolic blood pressure (DBP) $\geq 90 \mathrm{mmHg}$ on two occasions ( $4 \mathrm{~h}$ apart). PE was defined as PIH and new-onset proteinuria after 20 weeks of pregnancy $(\geq 300$ $\mathrm{mg} / 24 \mathrm{~h}$ or $\geq 2+$ dipstick mid-stream urine/catheter specimen of urine). A protein:creatinine ratio of $>30 \mathrm{mg} / \mathrm{mmol}$ of creatinine was generally used to confirm proteinuria. These criteria are an extension of those adopted by the International Society for the Study of Hypertension in Pregnancy $^{(9,18)}$.

The present study was conducted according to the guidelines laid down in the Declaration of Helsinki, and all procedures involving human subjects were approved by the Milton Keynes Research Ethics Committee (REC reference no. 08/H0603/46). Written informed consent was obtained from all subjects.

\section{Selenium status measurements}

Whole-blood samples were stored at $-20^{\circ} \mathrm{C}$ until thawed for analysis, and were analysed in duplicate. Se concentration was measured with full quality-control procedures by inductively coupled plasma-MS as described previously ${ }^{(9)}$. The CV for the blood Se assay was $0.25 \%$ at $1.4 \mu \mathrm{mol} / \mathrm{l}$ and $0 \cdot 17 \%$ at $3.0 \mu \mathrm{mol} / 1$.

Toenail Se concentration was measured in clippings collected from all ten toes at 16 weeks. Toenails were prepared for analysis as described previously ${ }^{(17)}$. Se content was determined using instrumental neutron activation analysis conducted at the Interfaculty Reactor Institute in Delft as described previously ${ }^{(17)}$. The analysis of NIST SRM $1577 \mathrm{~b}$ Bovine Liver gave a mean and combined standard uncertainty (forty-five determinations) of 0.73 (SD 0.005$) \mathrm{mg} / \mathrm{kg}$, compared with a certified mean of 0.74 (SD 0.02$) \mathrm{mg} / \mathrm{kg}$, indicating excellent accuracy of the method. The laboratory has an embedded quality-control system for quality assurance and management, which complies with the requirements of the International Standard ISO/IEC 17025:2005 and has been accredited by the Dutch Council for Accreditation since 1993.

SEPP1 concentrations were measured in the laboratory of Raymond Burk at the University of Vanderbilt using an ELISA as described previously ${ }^{(19)}$.

GPx3 activity was measured in plasma samples obtained at 12, 20 and 35 weeks at Griffith University as described previously ${ }^{(13)}$. Briefly, GPx activity was measured spectrophotometrically in triplicate in $10 \mu \mathrm{l}$ plasma samples. The rate of NADPH oxidation was recorded at $340 \mathrm{~nm}$ over $5 \mathrm{~min}$ using a Tecan Sunrise Absorbance Reader with Magellan Standard software (Tecan). The activity of GPx was calculated as units/ 1 of plasma (one unit of activity was defined as $1 \mu \mathrm{mol}$ of NADPH oxidised per min).

\section{Predictors of selenium status}

Demographic factors. Factors considered to be likely to affect Se status were as follows: baseline BMI; maternal age at recruitment; age at which the education of the mother ceased; occupation; ethnicity (Caucasian/other); smoking status (never smoked/ex-smoker). Occupation was used to code maternal 
social class according to the National Readership Demographic categories $^{(20)}$ and was classified into two groups: (1) A and B (middle class and above) and (2) C1 to E (lower middle class and below). BMI was coded as $<25$ or $\geq 25 \mathrm{~kg} / \mathrm{m}^{2}$.

Dietary factors. The FFQ containing eighteen items was based on the EPIC-Norfolk FFQ ${ }^{(21)}$, and was designed to collect information on the consumption of the following Se- and iodine-rich foods: seafood (white, oily and shellfish, fish fingers, and fish roe); meat (beef, beef burgers, pork and lamb, bacon, ham, sausages, and corned beef); poultry; Brazil nuts; offal (liver and liver products); dairy products (grouped as one item in the questionnaire); milk. Where participants had not given a frequency of consumption for individual food items in the FFQ $(n 7)$, these foods were coded as 'never or rarely'. The answers were converted to weekly portions, and for seafood, meat and poultry, the portions were summed to give a total. Food items were then recoded to reflect a high and low intake of the food item, i.e. intake above and below the median. For liver products and Brazil nuts, participants were dichotomised into either 'consumers' (any frequency of consumption) or 'non-consumers' (those who answered as 'never/rarely' consuming the products) due to small number of consumers.

\section{Statistical analyses}

Whole-blood Se, toenail Se and SEPP1 concentrations and GPX3 activity were not normally distributed, hence data are presented as medians and range values. Mann-Whitney $U$ tests were used to compare the concentrations/activity between the Se-treated and placebo groups.

The Wilcoxon matched-pair test was used to compare the changes in GPx3 activity from 12 to 20 weeks, 12 to 35 weeks and 20 to 35 weeks, and the change in whole-blood Se concentration from 12 to 35 weeks in the Se-treated and placebo groups.

Correlations were analysed by Spearman's rank correlation test. The Mann-Whitney test was used to compare the differences in whole-blood Se and toenail Se concentrations between the groups. A general linear model was used on log-transformed whole-blood Se and toenail Se concentrations to adjust the dietary analysis by those demographic factors that were significantly associated with Se status in univariate analysis. A series of models was constructed where each individual dietary factor was entered separately into a model, with social class, maternal age and age at which the education of the mother ceased being confounders.

We explored the effect of known ${ }^{(7)}$ and potential Se-related risk factors individually on the development of PE and $\mathrm{PIH}$ combined (PE/PIH) by multiple logistic regression. Factors that showed significance individually were then entered into a forward logistic regression model.

Subgroup analysis by compliance. A small number of women $(n$ ) $)$ in the Se-treated group took very few tablets $(\leq 23 \%)$. All the other women took $60 \%$ or more of those they could have taken (expressed as a percentage of the number of days between starting treatment and the delivery of the baby); hence, the forward logistic regression modelling was repeated after excluding Se-treated women who took $<60 \%$ of their treatment pills.

Significance was set at $P<0.05$, and analyses were conducted using the Statistical Package for the Social Sciences (version 21.0; SPSS, Inc.).

\section{Results}

\section{Selenium status}

Baseline measurements. Toenail Se concentration (16 weeks) and pre-treatment GPx3 activity (12 weeks) are presented in Table 1. There were no significant differences observed between the two treatment groups at baseline. Previously published $^{(9)}$ pre-treatment values of whole-blood Se concentration (12 weeks) in the same study are also presented in Table 1 to complete the dataset of Se status.

Baseline whole-blood Se concentration (12 weeks) was significantly correlated with the concentration of Se in toenails clipped at 16 weeks (Spearman's $\rho=0.447, P<0.001$ ), as shown in Fig. 1, but not with GPx3 activity measured at 12 weeks (Spearman's $\rho=0.042, P=0.533$ ).

Toenail Se concentration was significantly negatively, albeit weakly, correlated with DBP at baseline (Spearman's $\rho=-0 \cdot 135, P=0 \cdot 047)$.

Effect of treatment on selenium status and plasma glutathione peroxidase activity. Table 1 presents the data for GPx3 activity measured at 20 and 35 weeks. Previously published $^{(9)}$ Se concentration in whole blood at 35 weeks and SEPP1 concentration in plasma at 35 weeks following treatment with Se or placebo are also presented for completeness.

There was no significant difference observed in GPx3 activity between the Se-treated and placebo groups at either 20 or 35 weeks. However, using the Wilcoxon matched-pair test, GPx3 activity increased in the Se-treatment group only, from 12 to 20 weeks $(P=0.025)$ and from 12 to 35 weeks $(P=0.014)$, although there was no further increase in the activity from 20 to 35 weeks $(P=0 \cdot 219)$.

Effect of demographic and dietary factors on selenium status. Baseline whole-blood Se and toenail Se concentrations were significantly correlated, though weakly, with maternal age (Spearman's $\rho=0 \cdot 18, P=0.006$ and $\rho=0 \cdot 16$, $P=0 \cdot 018$, respectively) and with age at which the education of the mother ceased (Spearman's $\rho=0.17, P=0.009$ and $\rho=0 \cdot 20, P=0 \cdot 004$, respectively).

The effect of other demographic and dietary factors on Se status is summarised in Table 2. Women who were classified as middle class and above had a significantly higher se status as measured in both whole blood and toenails than those classified as lower middle class and below. Se status was not significantly affected by smoking status (never smoker or ex-smoker), ethnicity or BMI.

Whole-blood and toenail Se concentrations were significantly higher in consumers of Brazil nuts $(P=0.005$ and $P=0.03$, respectively); however, after adjusting for demographic factors, the difference in toenail Se concentration lost significance. Women who reported consuming at least two portions of seafood (white fish, oily fish or other seafood) per week had a 
significantly higher concentration of Se in both whole blood and toenails ( $P=0.001$ for each); the significance disappeared after adjustment, but remained close to significance for whole-blood Se concentration $(P=0.054)$. Intake of dairy products, meat and poultry, or liver did not significantly affect Se status (whole blood and toenails). Although intake of cows' milk was associated with toenail Se status, this association lost significance after adjustment.

\section{Hypertensive conditions of pregnancy}

Data on pregnancy outcome were available for 227 women, twenty of whom developed a hypertensive condition (PE $n 11$ and PIH $n$ 9).

Factors affecting the development of pregnancy-induced hypertension/pre-eclampsia. We explored the effect of a number of relevant factors on the risk of developing PE/PIH. DBP, maternal age, history of PE in mother or sister, and BMI are known risk factors for the development of PE or $\mathrm{PIH}^{(7)}$. We also investigated the effect of parameters of Se status (whole-blood Se concentration at 12 and 35 weeks, toenail Se concentration at 16 weeks, and SEPP1 concentration at 35 weeks) and treatment (Se $v$. placebo). Logistic regression on risk factors assessed individually showed that DBP, BMI and toenail Se concentration were the only factors that significantly affected the combined PE/PIH outcome; both SEPP1 concentration and treatment failed to reach significance (see Table 3). Although social class was significantly associated with 12-week whole-blood Se and toenail Se concentrations (Table 2), it was not significantly associated with PE/PIH $(P=0.396)$ and was therefore excluded from the model. When a stepwise model was run with only significant or near-significant factors entered into the model (SEPP1 was excluded as it was highly associated with treatment: mean $5.13 v .2 .95 \mathrm{mg} / \mathrm{l}$ for the Se-treated and placebo groups, respectively, $P<0.0005$ ), baseline DBP (OR $1 \cdot 10,95 \%$ CI $1 \cdot 03,1 \cdot 18$ ), BMI (OR $1 \cdot 13,95 \%$ CI $1 \cdot 00,1 \cdot 27$ ) and toenail Se concentration (OR $0.38,95 \%$ CI $0 \cdot 17,0.87$ ) remained significant, with treatment again failing to reach significance $(P=0.067)$ (adjusted model 1 ; Table 3). However, when the model was rerun after the non-compliers were excluded (i.e. Se-treated women who took $<60 \%$ of their treatment pills; for explanation see the Experimental methods section), treatment (Se $v$. placebo) became significant (OR $0 \cdot 297,95 \%$ CI $0.089,0.995, P=0.049$ ) (adjusted model 2; Table 3).

Based on adjusted model 2 (Table 3), women with $1 \mathrm{~mm} \mathrm{Hg}$ higher DBP at baseline were 1.12 times more likely to develop PE/PIH than other women, those with $0 \cdot 1 \mu \mathrm{g} / \mathrm{g}$ higher toenail Se concentration were only 0.32 times as likely to develop PE/PIH than other women, and those who consumed $60 \%$ or more of their Se tablets were only 0.30 times as likely to develop PE/PIH than women who took placebo.

The median toenail Se concentration in women who developed PE/PIH was significantly lower than that in other women (0.57, range $0.46-0.64 v$. 0.61 , range $0.46-1 \cdot 11$; $P=0 \cdot 004)$. 


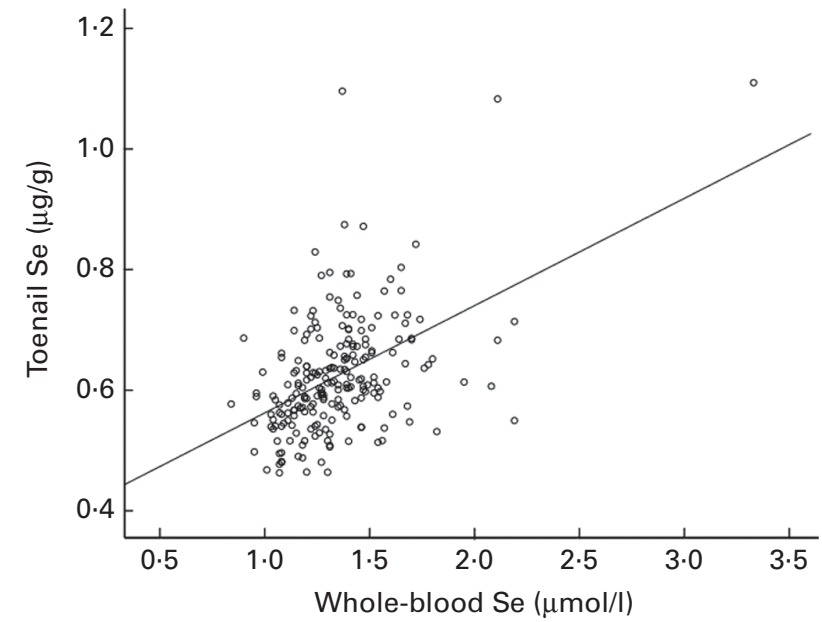

Fig. 1. Correlation between whole-blood selenium concentration at 12 weeks and toenail selenium concentration at 16 weeks (Spearman's $\rho=0.450$, $P<0.001)$ in UK pregnant women.

\section{Discussion}

\section{Baseline selenium status}

We chose to measure whole-blood Se concentration rather than serum/plasma Se concentration, as it is a longer-term measure of Se status and therefore less subject to day-to-day variation. However, this means that we have far fewer pregnancy data with which to compare our values. There is only one reported first-trimester value of approximately (read from a graph) $1 \mu \mathrm{mol} / \mathrm{l}^{(22)}$, which is lower than our baseline (12-week) value of $1.31 \mu \mathrm{mol} / \mathrm{l}$, but it was reported from a study in Serbia, a known low-Se area ${ }^{(23)}$. Other reported values are from the third trimester until delivery, and range from 0.76 to 0.8 in Serbia ${ }^{(22,24)}, 1.30$ to 1.36 in Kuwait ${ }^{(25,26)}$, to $1.51 \mu \mathrm{mol} / 1$ in Da-Ye, China ${ }^{(27)}$, and can be compared with the median value of $1.16 \mu \mathrm{mol} / \mathrm{l}$ found in the present study for the placebo group at 35 weeks of gestation. Hence, whole-blood Se concentration in our pregnant population was a little lower than the middle of the range observed in the few other populations for whom data were available.

The median toenail Se concentration in clippings taken at 16 weeks of gestation (laid down before conception) was $0.61 \mu \mathrm{g} / \mathrm{g}$, almost identical to the median value of $0.62 \mu \mathrm{g} / \mathrm{g}$ found in pregnant controls in our previous study ${ }^{(17)}$. This value is similar to that of toenail Se concentrations measured in women from The Netherlands (mean $0.58-0.72 \mu \mathrm{g} / \mathrm{g}$ ), but considerably lower than in women from the USA (mean $0.75-0.92 \mu \mathrm{g} / \mathrm{g})^{(17)}$

The median baseline GPx3 activity was 72.4 units/1 (Table 1). This is considerably lower than other values of GPx3 activity measured in other studies of pregnant women in the same laboratory, i.e. mean GPx3 activities of 84 and 104 units/1 were found in cohorts of US and Australian women in the second trimester of pregnancy, respectively (Vanderlelie et al., unpublished results). These values can more properly be compared with the value of 75.4 units/1 reported in the present study for the placebo group in the second trimester. Hence, it can be concluded that GPx3 activity was low in this UK pregnant population, probably reflecting a Se intake that is insufficient to optimise plasma GPx activity ${ }^{(28,29)}$.

Women who were older, of higher social class (based on occupation) and left education at a later age had significantly higher Se status (whole blood and toenails). These findings are in agreement with those of the 2001 Adult UK National Diet and Nutrition Survey where higher plasma Se concentration was associated with older age, better education and higher earnings $(P \leq 0 \cdot 001)^{(30)}$.

With regard to diet, the consumption of Brazil nuts, known to be high in Se, significantly increased whole-blood Se concentration, although its significant effect on toenail Se concentration disappeared after adjustment; however, the number of Brazil nut consumers was small ( $n$ 26). The consumption of seafood tended to increase both whole-blood and toenail Se concentrations.

\section{Effect of treatment: longitudinal effects on status}

As expected, there was a significant increase in whole-blood Se concentration in the Se-treated group from 12 to 35 weeks of gestation. This reflects both an increase in the concentrations of the plasma selenoproteins, SEPP1 and, to a lesser extent, GPx3 (see below) and, to an unknown degree, a non-specific incorporation of Se as selenomethionine into proteins including albumin and erythrocyte $\mathrm{Hb}$. Over the corresponding period, a significant decrease in whole-blood Se concentration was observed in the placebo group, which can be interpreted as partly due to the increase in plasma volume that occurs in pregnancy and partly due to placental transfer of Se to the fetus by SEPP1 via the apoER2 receptor ${ }^{(9)}$. It would appear that pregnancy is putting pressure on the Se stores of these women whose Se status may be inadequate to deal with fetal demands.

Women in the Se-treated group had a median SEPP1 concentration that was $77 \%$ higher at 35 weeks than those in the placebo group. Baseline SEPP1 concentration was quite low in this cohort, and even after supplementation, the suggested plateau at $6.5-7 \mathrm{mg} / \mathrm{l}$ was not reached in many of the supplemented women, suggesting a requirement for a higher dose or longer treatment period ${ }^{(9)}$.

In Se-supplemented women alone, a small but significant increase in GPx3 activity was found between 12 and 20 weeks, which was also observed between 12 and 35 weeks, despite a modest decrease between 20 and 35 weeks. Although this might imply that GPx 3 activity was already almost maximised at baseline, this interpretation does not fit with the fact that GPx3 activity in UK pregnant women was considerably lower than that in other cohorts measured in the same laboratory. It is more likely that additional Se is being prioritised for the synthesis of other selenoproteins, notably SEPP1, which at 35 weeks was substantially higher in the Se-treated group than in the placebo group. Studies in both cell and animal models have suggested that a hierarchical selenoprotein expression pattern occurs during deprivation and supplementation states ${ }^{(31-33)}$. Furthermore, as mitochondrial oxidative stress increases over the course of pregnancy, intracellular 
Table 2. Predictors of selenium status

(Number of women; median values and interquartile ranges)

\begin{tabular}{|c|c|c|c|c|c|c|c|c|c|c|}
\hline & \multicolumn{5}{|c|}{ 12-week whole-blood Se $(\mu \mathrm{mol} / \mathrm{l})$} & \multicolumn{5}{|c|}{ Toenail Se $(\mu \mathrm{g} / \mathrm{g})$} \\
\hline & $\begin{array}{l}\text { Women } \\
\quad(n)\end{array}$ & Median & $\begin{array}{l}\text { Interquartile } \\
\text { range }\end{array}$ & $P$ & Adjusted $P^{\star}$ & $\begin{array}{l}\text { Women } \\
(n)\end{array}$ & Median & $\begin{array}{l}\text { Interquartile } \\
\text { range }\end{array}$ & $P$ & Adjusted $P^{\star}$ \\
\hline \multicolumn{11}{|l|}{ Demographic factors } \\
\hline \multicolumn{11}{|l|}{ Social class } \\
\hline Middle and above & 101 & 1.33 & $1.22-1.48$ & \multirow[t]{2}{*}{0.027} & \multirow[t]{2}{*}{ NAt } & 98 & 0.63 & $0.59-0.69$ & \multirow[t]{2}{*}{0.004} & \multirow[t]{2}{*}{ NAt } \\
\hline $\begin{array}{l}\text { Lower middle and } \\
\text { below }\end{array}$ & 128 & $1 \cdot 30$ & $1 \cdot 14-1.45$ & & & 120 & 0.60 & $0.55-0.65$ & & \\
\hline \multicolumn{11}{|l|}{ Smoking status } \\
\hline Never smoked & 156 & 1.32 & $1.19-1.47$ & \multirow[t]{2}{*}{0.529} & \multirow[t]{2}{*}{ NA† } & 148 & 0.61 & $0.57-0.67$ & \multirow[t]{2}{*}{0.261} & \multirow[t]{2}{*}{ NA† } \\
\hline Ex-smoker & 73 & 1.30 & $1.18-1.46$ & & & 70 & 0.61 & $0.54-0.66$ & & \\
\hline \multicolumn{11}{|l|}{ Ethnicity } \\
\hline Caucasian & 213 & 1.31 & $1.18-1.47$ & \multirow[t]{2}{*}{0.438} & \multirow[t]{2}{*}{ NA† } & 202 & 0.61 & $0.56-0.67$ & \multirow[t]{2}{*}{0.869} & \multirow[t]{2}{*}{ NAt } \\
\hline Other & 16 & 1.34 & $1.25-1.48$ & & & 16 & 0.62 & $0.55-0.63$ & & \\
\hline \multicolumn{11}{|l|}{$\mathrm{BMI}$} \\
\hline$<25 \mathrm{~kg} / \mathrm{m}^{2}$ & 138 & 1.35 & $1.19-1.48$ & \multirow[t]{2}{*}{0.183} & \multirow[t]{2}{*}{$\mathrm{NA} \dagger$} & 131 & 0.61 & $0.56-0.67$ & \multirow[t]{2}{*}{0.841} & \multirow[t]{2}{*}{ NA† } \\
\hline$\geq 25 \mathrm{~kg} / \mathrm{m}^{2}$ & 91 & 1.29 & $1.16-1.44$ & & & 87 & 0.61 & $0.56-0.68$ & & \\
\hline \multicolumn{11}{|l|}{ Dietary factors } \\
\hline \multicolumn{11}{|l|}{ Seafood } \\
\hline$<2$ portions/week & 98 & 1.27 & $1.14-1.41$ & \multirow[t]{2}{*}{0.010} & \multirow[t]{2}{*}{0.054} & 95 & 0.59 & $0.54-0.65$ & 0.012 & 0.078 \\
\hline$\geq 2$ portions/week & 121 & 1.36 & $1.21-1.48$ & & & 118 & 0.63 & $0.57-0.69$ & & \\
\hline Meat & & & & & & & & & & \\
\hline$<7$ portions/week & 108 & 1.33 & $1.19-1.47$ & 0.540 & 0.299 & 107 & 0.61 & $0.56-0.66$ & 0.729 & 0.610 \\
\hline$\geq 7$ portions/week & 111 & 1.30 & $1.16-1.46$ & & & 106 & 0.61 & $0.56-0.68$ & & \\
\hline Brazil nuts & & & & & & & & & & \\
\hline Non-consumer & 193 & 1.30 & $1.16-1.46$ & 0.005 & 0.040 & 187 & 0.60 & $0.56-0.66$ & 0.034 & 0.147 \\
\hline Consumer & 26 & 1.40 & $1.31-1.61$ & & & 26 & 0.66 & $0.60-0.72$ & & \\
\hline Offal (liver) & & & & & & & & & & \\
\hline Non-consumer & 182 & 1.31 & $1.18-1.47$ & 0.583 & 0.765 & 176 & 0.61 & $0.56-0.66$ & 0.702 & 0.804 \\
\hline Consumer & 37 & 1.35 & $1.22-1.45$ & & & 37 & 0.62 & $0.56-0.72$ & & \\
\hline Dairy products & & & & & & & & & & \\
\hline$\leq 1$ portion $/ \mathrm{d}$ & 110 & 1.30 & $1.16-1.45$ & 0.423 & 0.672 & 107 & 0.61 & $0.56-0.67$ & 0.916 & 0.112 \\
\hline$>1$ portion/d & 109 & 1.32 & $1.19-1.48$ & & & 106 & 0.61 & $0.57-0.67$ & & \\
\hline Cows' milk & & & & & & & & & & \\
\hline$<280 \mathrm{ml} / \mathrm{d}$ & 146 & 1.32 & $1.18-1.46$ & 0.920 & 0.983 & 144 & 0.60 & $0.56-0.66$ & 0.016 & 0.083 \\
\hline$\geq 280 \mathrm{ml} / \mathrm{d}$ & 73 & 1.32 & $1.21-1.46$ & & & 69 & 0.63 & $0.57-0.70$ & & \\
\hline
\end{tabular}

NA, not applicable.

${ }^{*}$ Conducted on log-transformed Se variables; a series of general linear models were constructed where each individual dietary factor was entered into a separate model, with maternal age, age at which the education of the mother ceased and social class (dichotomised) being confounders.

$\dagger$ Demographic factors were used to adjust the $P$ values for the dietary factors only.

GPx isoforms may be preferentially expressed over extracellular GPx3 for the protection of the trophoblast ${ }^{(34,35)}$.

\section{Risk of development of hypertensive conditions of pregnancy}

We combined the outcomes of PE and PIH because the distinction between the two is not always completely clear; $15-45 \%$ of women with PIH will eventually develop $\mathrm{PE}^{(36,37)}$, particularly when PIH presents early in gestation ${ }^{(38)}$. Indeed, $\mathrm{PIH}$ associated with features of PE other than proteinuria, such as hyperuricaemia or intra-uterine growth retardation, is now regarded as an atypical variant of $\mathrm{PE}^{(39)}$. Furthermore, there are immunological similarities between the conditions, both of which show a general depression in immunocompetent lymphocytes with a higher overall level of T-cell activation ${ }^{(40)}$, suggesting some commonality in aetiology. Increased oxidative stress is also a feature observed in both conditions ${ }^{(41,42)}$.

We previously found that women supplemented with Se had a significantly lower risk of the combined hypertensive outcomes than those treated with placebo (adjusted OR 0.35,
$P=0.044)^{(9)}$. PE is associated with increased systemic (vascular) inflammation relative to normal pregnancy ${ }^{(43)}$; although this has not been shown for PIH as such, the effect of Se on the risk of developing PE/PIH may be partly due to the ability of selenoproteins to counteract inflammation ${ }^{(44,45)}$. Se supply is known to affect the synthesis and actions of eicosanoids, important modulators of inflammation, platelet activation, blood pressure and the immune response ${ }^{(44,45)}$; for instance, under oxidative stress, Se-deficient endothelial cells produce less of the vasodilatory eicosanoid, prostacyclin ${ }^{(45)}$.

A further important anti-inflammatory mechanism of Se involves selenoprotein S (SELS). SELS manages inflammation control in the endoplasmic reticulum by assisting in the retrotranslocation of misfolded proteins from the endoplasmic reticulum into the cytosol $^{(46)}$. Endoplasmic-reticulum stress is known to be involved in the pathophysiology of $\mathrm{PE}^{(47)}$. A SNP in the gene encoding SELS has been correlated with serum concentrations of pro-inflammatory cytokines ${ }^{(48)}$ and with the risk of developing $\mathrm{PE}$ in a large Norwegian cohort ${ }^{(16)}$.

Of the known risk factors for hypertensive conditions of pregnancy $^{(7)}$ treated individually, only baseline DBP and 
BMI reached significance in the present study cohort. Of the Se-related risk factors, toenail Se, which measures prepregnancy Se status, was by far the most significant determinant of PE/PIH. When only significant or near-significant factors were entered into a stepwise model, toenail se became a more significant determinant with a larger effect size than BMI; after exclusion of Se-treated non-compliers, Se treatment also significantly reduced the odds of developing PE/PIH.

The strong effect of pre-pregnancy Se status is reflected in the significant difference in median toenail Se concentration between women who developed PE/PIH and other women. This result is consistent with our previous finding in the same region of the UK demonstrating significantly lower toenail Se concentration in women with PE than that in matched pregnant controls ${ }^{(17)}$.

What can we conclude from these findings and particularly from the fact that pre-pregnant Se status (as measured in toenails) appears to be a more significant predictor than Se treatment started at 12 weeks? If Se is having its effect through antioxidant selenoproteins - it is known, for instance, that it has the capacity to up-regulate antioxidant systems and protect trophoblast cells from oxidative stress ${ }^{(49)}-$ it would need to be present at the time of a relevant pro-oxidant challenge ${ }^{(50)}$. Such a pro-oxidant challenge occurs at the initiation of intervillous blood flow at 8-10 weeks of gestation that is associated with a burst of oxidative stress ${ }^{(42,51)}$. Se supplementation did not start until 12 weeks and then only at a low dose, so it would have taken some time for antioxidant selenoenzymes to reach an adequate protective level; nonpregnant individuals supplemented with $100 \mu \mathrm{g}$ Se, as selenomethionine, took $60 \mathrm{~d}$ to reach a plateau in GPx3 activity $^{(52)}$.

Alternatively, is pre-pregnancy Se status more important in preventing hypertensive pregnancy conditions than status in pregnancy itself? The development of the oocyte, fertilisation and implantation are periconceptual events that could be affected by Se status ${ }^{(53,54)}$. Antioxidant selenoproteins can counteract excessive synthesis of reactive oxygen species that impairs oocyte maturation and embryo development ${ }^{(53,55)}$. The fact that periconceptual multivitamin/mineral use reduces the risk of developing PE suggests that an adequate status of protective vitamins and minerals is important before, or shortly after, conception ${ }^{(56,57)}$.

Se status in very early pregnancy might also affect PE/PIH through an effect on regulatory $\mathrm{T}\left(\mathrm{T}_{\text {reg }}\right)$ cells that are necessary, at least in the mouse, to maintain materno-fetal tolerance and a normal pregnancy outcome ${ }^{(58,59)}$. Indeed, $\mathrm{T}_{\text {reg }}$ cells are essential even before embryo implantation ${ }^{(60)}$. Dietary Se has been shown to increase the differentiation of naive $\mathrm{CD}^{+}$ $\mathrm{T}$ cells into $\mathrm{CD} 25^{+} \mathrm{Foxp}^{+} \mathrm{T}_{\text {reg }}$ cells in mice ${ }^{(44)}$, while $\mathrm{Se}$ treatment significantly increased the percentage of $T_{\text {reg }}$ cells and the expression of Foxp3 mRNA in a mouse model of autoimmune thyroid disease ${ }^{(61)}$.

A limitation of the present study was that it was not designed to determine hypertensive outcomes of pregnancy, therefore the study was not adequately powered for that end point. Although we attempted to capture the intake of Se-rich foods through a FFQ, the results need to be interpreted with caution because of the inherent limitations of the FFQ. 


\section{Conclusion}

We validated our first hypothesis that UK pregnant women have low Se status, as determined by the median value of a number of status parameters. We also validated our second hypothesis that Se status/Se supplementation affects the risk of developing hypertensive conditions of pregnancy; the odds of PE/PIH were significantly reduced in women with higher pre-pregnancy Se status (toenail Se) and in those supplemented with Se from 12 weeks of gestation.

In conclusion, UK women need to improve their Se status, ideally before pregnancy, as our data suggest that prepregnancy status has a significant effect on the risk of developing hypertensive conditions of pregnancy. Although our simplified FFQ revealed that consumption of Brazil nuts was associated with higher whole-blood Se concentration, we cannot recommend them as a means of increasing Se status as they contain both $\mathrm{Ba}$, at a level where consumption of two nuts per $\mathrm{d}$ could exceed the reference dose, and $\mathrm{Ra}\left(\mathrm{Ra}^{228}\right)$, with an activity of $6-133 \mathrm{~Bq} / \mathrm{kg}^{(62-64)}$. Offal and seafood are other rich sources of $\mathrm{Se}^{(65)}$ and higher consumption of seafood was marginally associated with better Se status; however, these foods are often unpopular. Hence, it is likely that many women will need to take a Se-containing supplement (e.g. as part of a multivitamin and mineral pregnancy supplement) at least as soon as they know they are pregnant, and preferably when planning pregnancy. We gave a supplement of $60 \mu \mathrm{g} \mathrm{Se} / \mathrm{d}$; however, a dose of $100 \mu \mathrm{g} \mathrm{Se} / \mathrm{d}$ would probably be preferable in women who only commence supplementation when pregnancy is confirmed, as even at that higher dose, $60 \mathrm{~d}$ were required for a plateau to be reached in GPx3 activity $^{(52)}$.

A study in a larger cohort of pregnant women is needed to confirm these findings.

\section{Acknowledgements}

The authors are extremely grateful to all the women who took part in the study and the team at the John Radcliffe Hospital, especially Libby Searle, research midwife, who recruited the women. The authors thank Dr Christine Sieniawska of the Trace Element Unit, Southampton University Hospital NHS Trust for the analysis of Se in whole blood, the laboratory of Raymond Burk, University of Vanderbilt, for the analyses of SEPP1, and Mehmet Sarilar and Menno Blaauw of TU Delft Reactor Instituut for the analysis of toenails.

The present study was supported by the Wellcome Trust Project Grant 083918/Z/07/Z (to M. P. R., and C. W. G. R); Nestlé Nutrition Institute Fellowship (to J. M.); MRC Population Health Scientist Fellowship (to S. C. B.); SEPP1 analyses at the laboratory of Raymond Burk, University of Vanderbilt were supported by grant NIH ES02497; toenail analysis at TU Delft Reactor Instituut was supported by the European Commission under the 7 th Framework Programme through the 'Research Infrastructures' action of the 'Capacities' Programme (NMI3-II grant number 283883).

The authors' contributions are as follows: M. P. R. and C. W. G. R. designed the research; J. W. measured GPx3 activity;
S. C. B. advised on the data analysis and analysed the FFQ; P. W., S. C. B., J. M. and J. J. V. conducted the statistical analysis; M. P. R. wrote the paper; S. C. B., P. W. and C. W. G. R. revised the paper; M. P. R. had primary responsibility for final content. All authors read and approved the final manuscript.

None of the authors has any conflict of interest to declare.

\section{References}

1. Steegers EA, von Dadelszen P, Duvekot JJ, et al. (2010) Pre-eclampsia. Lancet 376, 631-644.

2. Hutcheon JA, Lisonkova S \& Joseph KS (2011) Epidemiology of pre-eclampsia and the other hypertensive disorders of pregnancy. Best Pract Res Clin Obstet Gynaecol 25, 391-403.

3. Wilson BJ, Watson MS, Prescott GJ, et al. (2003) Hypertensive diseases of pregnancy and risk of hypertension and stroke in later life: results from cohort study. BMJ 326, 845.

4. Bellamy L, Casas JP, Hingorani AD, et al. (2007) Preeclampsia and risk of cardiovascular disease and cancer in later life: systematic review and meta-analysis. BMJ 335, 974.

5. Valdiviezo C, Garovic VD \& Ouyang P (2012) Preeclampsia and hypertensive disease in pregnancy: their contributions to cardiovascular risk. Clin Cardiol 35, 160-165.

6. Kurabayashi T, Mizunuma H, Kubota T, et al. (2013) Pregnancy-induced hypertension is associated with maternal history and a risk of cardiovascular disease in later life: Japanese cross-sectional study. Maturitas 75, 227-231.

7. Duckitt K \& Harrington D (2005) Risk factors for preeclampsia at antenatal booking: systematic review of controlled studies. BMJ 330, 565.

8. Palmsten K, Buka SL \& Michels KB (2010) Maternal pregnancy-related hypertension and risk for hypertension in offspring later in life. Obstet Gynecol 116, 858-864.

9. Rayman MP, Searle E, Kelly L, et al. (2014) Effect of selenium on markers of risk of pre-eclampsia in UK pregnant women: a randomised, controlled, pilot trial. BrJ Nutr 112, 99-111.

10. Han L \& Zhou SM (1994) Selenium supplement in the prevention of pregnancy induced hypertension. Chin Med J (Engl) 107, 870-871.

11. Vanderlelie JJ \& Perkins AV (2011) Selenium and preeclampsia: a global perspective. Pregnancy Hypertens 1, 213-224.

12. Walsh SW \& Wang Y (1993) Deficient glutathione peroxidase activity in preeclampsia is associated with increased placental production of thromboxane and lipid peroxides. $A m J$ Obstet Gynecol 169, 1456-1461.

13. Vanderlelie J, Venardos K, Clifton VL, et al. (2005) Increased biological oxidation and reduced anti-oxidant enzyme activity in pre-eclamptic placentae. Placenta 26, 53-58.

14. Atamer Y, Koçyigit Y, Yokus B, et al. (2005) Lipid peroxidation, antioxidant defense, status of trace metals and leptin levels in preeclampsia. Eur J Obstet Gynecol Reprod Biol 119, 60-66.

15. Mistry HD, Wilson V, Ramsay MM, et al. (2008) Reduced selenium concentrations and glutathione peroxidase activity in preeclamptic pregnancies. Hypertension 52, 881-888.

16. Moses EK, Johnson MP, Tommerdal L, et al. (2008) Genetic association of preeclampsia to the inflammatory response gene SEPS1. Am J Obstet Gynecol 198, 336e1-336e5.

17. Rayman MP, Bode P \& Redman CWG (2003) Low selenium status is associated with the occurrence of the pregnancy disease preeclampsia in women from the United Kingdom. Am J Obstet Gynecol 189, 1343-1349.

18. Davey DA \& MacGillivray I (1988) The classification and definition of the hypertensive disorders of pregnancy. $A m \mathrm{~J}$ Obstet Gynecol 158, 892-898. 
19. Burk RF, Norsworthy BK, Hill KE, et al. (2006) Effects of chemical form of selenium on plasma biomarkers in a high-dose human supplementation trial. Cancer Epidemiol Biomarkers Prev 15, 804-810.

20. National Readership Survey (2014) National Readership Survey social grade. http://www.nrs.co.uk/lifestyle-data/ (accessed 30 April 2014).

21. Bingham SA, Welch AA, McTaggart A, et al. (2001) Nutritional methods in the European Prospective Investigation of Cancer in Norfolk. Public Health Nutr 4, 847-858.

22. Mihailovic M, Cvetkovic M, Ljubic A, et al. (2000) Selenium and malondialdehyde content and glutathione peroxidase activity in maternal and umbilical cord blood and amniotic fluid. Biol Trace Elem Res 73, 47-54.

23. Rayman MP (2005) Selenium in cancer prevention: a review of the evidence and mechanism of action. Proc Nutr Soc 64 , 527-542.

24. Kosanovic M, Jokanovic M, Jevremovic M, et al. (2002) Maternal and fetal cadmium and selenium status in normotensive and hypertensive pregnancy. Biol Trace Elem Res 89, 97-103.

25. Al-Saleh E, Nandakumaran M, Al-Shammari M, et al. (2004) Assessment of maternal-fetal status of some essential trace elements in pregnant women in late gestation: relationship with birth weight and placental weight. J Matern Fetal Neonatal Med 16, 9-14.

26. Al-Saleh E, Nandakumaran M, Al-Shammari M, et al. (2004) Maternal-fetal status of copper, iron, molybdenum, selenium and zinc in patients with gestational diabetes. J Matern Fetal Neonatal Med 16, 15-21.

27. Zhang Y, Zhao Y, Wang J, et al. (2004) Effects of zinc, copper, and selenium on placental cadmium transport. Biol Trace Elem Res 102, 39-49.

28. Rayman MP (2002) The argument for increasing selenium intake. Proc Nutr Soc 61, 203-215.

29. Rayman MP (2000) The importance of selenium to human health. Lancet 356, 233-241.

30. Stranges S, Laclaustra M, Ji C, et al. (2010) Higher selenium status is associated with adverse blood lipid profile in British adults. J Nutr 140, 81-87.

31. Behne D, Hilmert H, Scheid S, et al. (1988) Evidence for specific selenium target tissues and new biologically important selenoproteins. Biochim Biophys Acta 966, 12-21.

32. Hill KE, Lyons PR \& Burk RF (1992) Differential regulation of rat liver selenoprotein mRNAs in selenium deficiency. Biochem Biophys Res Commun 185, 260-263.

33. Ashton K, Hooper L, Harvey LJ, et al. (2009) Methods of assessment of selenium status in humans: a systematic review. Am J Clin Nutr 89, 2025S-2039S.

34. Khera A, Vanderlelie JJ \& Perkins AV (2013) Selenium supplementation protects trophoblast cells from mitochondrial oxidative stress. Placenta 34, 594-598.

35. Brigelius-Flohe R (1999) Tissue-specific functions of individual glutathione peroxidases. Free Radic Biol Med 27, 951-965.

36. Davis GK, Mackenzie C, Brown MA, et al. (2007) Predicting transformation from gestational hypertension to preeclampsia in clinical practice: a possible role for 24 hour ambulatory blood pressure monitoring. Hypertens Pregnancy 26, 77-87.

37. Barton JR, O'Brien JM, Bergauer NK, et al. (2001) Mild gestational hypertension remote from term: progression and outcome. Am J Obstet Gynecol 184, 979-983.

38. Saudan P, Brown MA, Buddle ML, et al. (1998) Does gestational hypertension become pre-eclampsia? $\mathrm{Br} J$ Obstet Gynaecol 105, 1177-1184.
39. Brown MA \& de Swiet M (1999) Classification of hypertension in pregnancy. Baillieres Best Pract Res Clin Obstet Gynaecol 13, 27-39.

40. Mahmoud F, Omu A, Abul H, et al. (2003) Lymphocyte subpopulations in pregnancy complicated by hypertension. J Obstet Gynaecol 23, 20-26.

41. Chen G, Wilson R, Cumming G, et al. (1993) Prostacyclin, thromboxane and antioxidant levels in pregnancy-induced hypertension. Eur J Obstet Gynecol Reprod Biol 50, 243-250.

42. Burton GJ \& Jauniaux E (2004) Placental oxidative stress: from miscarriage to preeclampsia. J Soc Gynecol Investig 11, 342-352.

43. Redman CW, Sacks GP \& Sargent IL (1999) Preeclampsia: an excessive maternal inflammatory response to pregnancy. Am J Obstet Gynecol 180, 499-506.

44. Huang Z, Rose AH \& Hoffmann PR (2012) The role of selenium in inflammation and immunity: from molecular mechanisms to therapeutic opportunities. Antioxid Redox Signal 16, 705-743.

45. Mattmiller SA, Carlson BA \& Sordillo LM (2013) Regulation of inflammation by selenium and selenoproteins: impact on eicosanoid biosynthesis. J Nutr Sci 2, e28.

46. Gao Y, Feng HC, Walder K, et al. (2004) Regulation of the selenoprotein SelS by glucose deprivation and endoplasmic reticulum stress - SelS is a novel glucose-regulated protein. FEBS Lett 563, 185-190.

47. Burton GJ, Yung HW, Cindrova-Davies T, et al. (2009) Placental endoplasmic reticulum stress and oxidative stress in the pathophysiology of unexplained intrauterine growth restriction and early onset preeclampsia. Placenta 30, S43-S48.

48. Curran JE, Jowett JB, Elliott KS, et al. (2005) Genetic variation in selenoprotein $S$ influences inflammatory response. Nat Genet 37, 1234-1241.

49. Watson M, van Leer L, Vanderlelie JJ, et al. (2012) Selenium supplementation protects trophoblast cells from oxidative stress. Placenta 33, 1012-1019.

50. Roberts JM, Myatt L, Spong CY, et al. (2010) Vitamins C and E to prevent complications of pregnancy-associated hypertension. $N$ Engl J Med 362, 1282-1291.

51. Jauniaux E, Watson AL, Hempstock J, et al. (2000) Onset of maternal arterial blood flow and placental oxidative stress. A possible factor in human early pregnancy failure. $\mathrm{Am} \mathrm{J}$ Pathol 157, 2111-2122.

52. Neve J, Vertongen F \& Capel P (1988) Selenium supplementation in healthy Belgian adults: response in platelet glutathione peroxidase activity and other blood indices. Am J Clin Nutr 48, 139-143.

53. Poston L, Igosheva N, Mistry HD, et al. (2011) Role of oxidative stress and antioxidant supplementation in pregnancy disorders. Am J Clin Nutr 94, Suppl. 6, 1980S-1985S.

54. Ceko MJ, Hummitzsch K, Hatzirodos N, et al. (2014) X-ray fluorescence imaging and other analyses identify selenium and GPX1 as important in female reproductive function. Metallomics (Epublication ahead of print version 27 November 2014).

55. Leese HJ, Baumann CG, Brison DR, et al. (2008) Metabolism of the viable mammalian embryo: quietness revisited. Mol Hum Reprod 14, 667-672.

56. Bodnar LM, Tang G, Ness RB, et al. (2006) Periconceptional multivitamin use reduces the risk of preeclampsia. Am J Epidemiol 164, 470-477.

57. Catov JM, Nohr EA, Bodnar LM, et al. (2009) Association of periconceptional multivitamin use with reduced risk of preeclampsia among normal-weight women in the Danish National Birth Cohort. Am J Epidemiol 169, 1304-1311. 
58. Somerset DA, Zheng Y, Kilby MD, et al. (2004) Normal human pregnancy is associated with an elevation in the immune suppressive $\mathrm{CD} 25^{+} \mathrm{CD}^{+}{ }^{+}$regulatory T-cell subset. Immunology 112, 38-43.

59. Leber A, Zenclussen ML, Teles A, et al. (2011) Pregnancy: tolerance and suppression of immune responses. Methods Mol Biol 677, 397-417.

60. Guerin LR, Prins JR \& Robertson SA (2009) Regulatory T-cells and immune tolerance in pregnancy: a new target for infertility treatment? Hum Reprod Update 15, 517-535.

61. Xue H, Wang W, Li Y, et al. (2010) Selenium upregulates $\mathrm{CD} 4(+) \mathrm{CD} 25(+)$ regulatory $\mathrm{T}$ cells in iodine-induced autoimmune thyroiditis model of NOD.H-2(h4) mice. Endocr J 57, 595-601.

62. Thomson CD, Chisholm A, McLachlan SK, et al. (2008) Brazil nuts: an effective way to improve selenium status. Am J Clin Nutr 87, 379-384.

63. U.S. Environmental Protection Agency (2005) Toxicological Review of Barium and Compounds. Washington, DC: U.S. Environmental Protection Agency.

64. Penna-Franca E, Fiszman M, Lobao N, et al. (1968) Radioactivity of Brazil nuts. Health Phys 14, 95-99.

65. Rayman MP (2012) Selenium and human health. Lancet 379, $1256-1268$. 